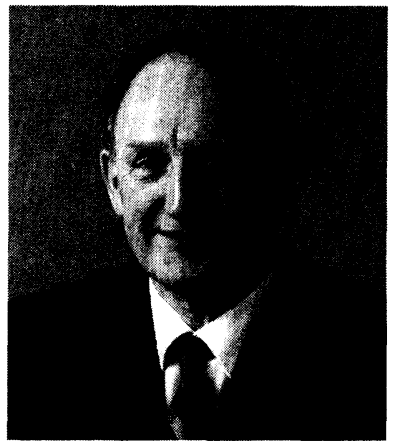

\section{The Year 1993 in Review: Part II}

This editorial is a continuation of the editorial in the February issue and presents some additional facts and figures about Volume 32 and activities during 1993.

Figure 1 shows the number of technical pages published in Optical Engineering each year since 1978.

Table 1 shows the outcome of papers received during 1991 and 1992. There are some small differences between the various percentages but they are probably not significant. The 1991 numbers are for papers received by my office from 1 December 1990 through 31 December 1991. The papers indicated as "closed" are papers that have been returned to the authors for significant revisions. If, after a reasonable amount of time, plus several reminders, I do not hear from the authors, then the file is closed. If the authors choose to resubmit after that action, the papers are treated as new submission - this occurs in very few instances.

\section{Activity in 1993}

The year 1993 was, again, a very busy year for the editorial offices in Rochester and Bellingham, with a record number of papers submitted (401), and hence record levels of activity in all the processes that we go through. Table 2 shows some of the important activities that we track; the percentage changes since 1992 are included. Of course, some of these activities relate to papers that were received in 1992 but were going through the revision process in 1993. The third entry "written reviews received" relates to the actual written reviews received, and does not include those responses taken over the phone, or those that simply state that the paper is acceptable in its present form, or the re-reviews of revised manuscripts when the reviewer states that the authors have made the appropriate revisions.

Figure 2 is a plot of the cumulative number of papers received by month for each of the last five years. These papers are the regularly submitted papers and the numbers do not include those submitted for special sections.

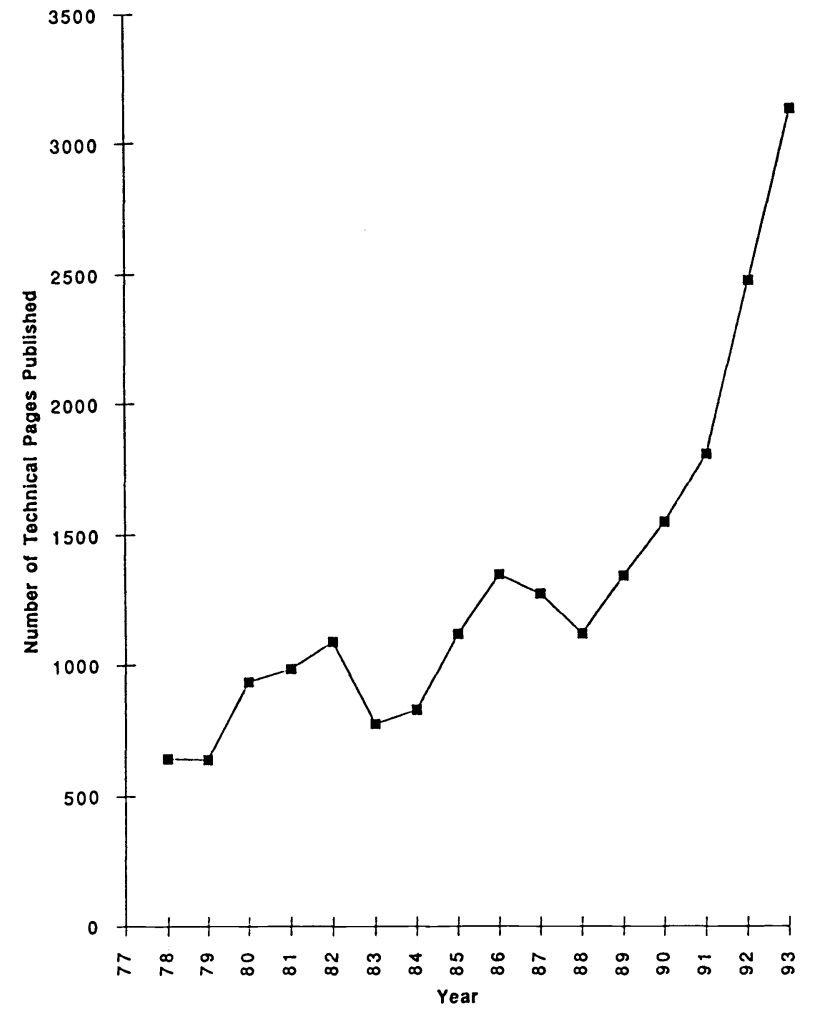

Fig. 1 Number of technical pages published per year from 1978 through 1993.

Table 1 Outcome of papers received in 1991 and 1992.

\begin{tabular}{lrr|}
\hline & 1991 & 1992 \\
\% accepted & 64.0 & 69.8 \\
\% rejected & 26.4 & 21.5 \\
\% closed & 7.0 & 5.8 \\
\% withdrawn & 1.3 & 2.6 \\
\% transferred & 1.3 & 0.3 \\
\hline
\end{tabular}




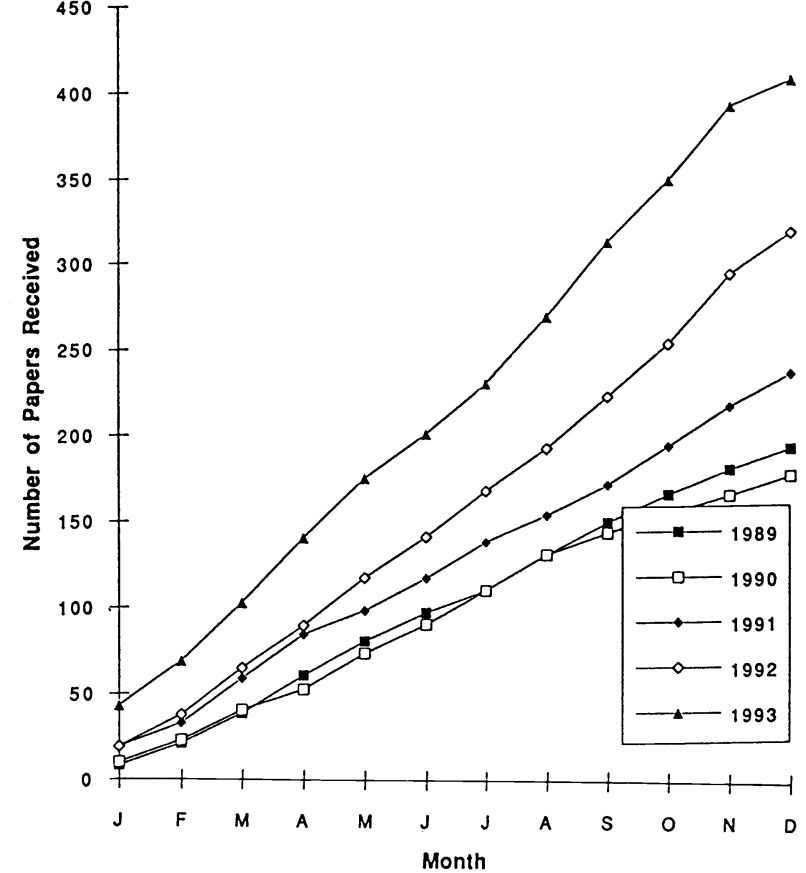

Fig. 2 Number of papers received per month from 1989 to 1993 (excluding special section papers).

\section{Status of Papers Received During 1993}

The 401 papers received during 1993 are in various stages of the editorial process. Table 3 summarizes the state of all these papers as of the end of December 1993.

\section{Issues}

As we move forward with Volume 33 and beyond, we need to be concerned about the timely flow of papers, particularly the time from final acceptance to publication. The minimum time for that step is really five months to allow for galley proofs to be sent out and returned from around the world. Readers will probably be aware that the journal is sent to the printer from headquarters three weeks before it is mailed. We will try our best to get as close to that five-month minimum as possible but it will take some work and careful scheduling.

\section{Packaging of the Journal}

You may have noticed that, starting with last month's issue, we have been shrinkwrapping the U.S. copies of the journal. (The overseas copies have always been mailed in envelopes.)
Table 2 Activity during 1993.

$\begin{array}{lrc}\text { Regular papers received } & 401 & +28.3 \% \\ \text { Reviewers solicited } & 1047 & +30.7 \% \\ \text { Written reviews received } & 727 & +56.3 \% \\ \text { Revised manuscripts received } & 257 & +60.6 \% \\ \text { Accepted } & 261 & +35.9 \% \\ \text { Rejected } & 100 & +96.7 \% \\ \text { Withdrawn } & 7 & - \\ \text { Closed } & 53 & +211.8 \% \\ \text { Returned to author(s) for revision } & 307 & +66.8 \% \\ \text { Papers received and accepted for } & & \\ \quad \text { special sections } & 198 & +18.6 \% \\ \text { Papers for Communications Section } & 13 & -\end{array}$

Table 3 Status of papers received during 1993 as of December 31.

$\begin{array}{lr}\text { Published } & 9 \\ \text { In press } & 147 \\ \text { Rejected } & 66 \\ \text { In review } & 76 \\ \text { In revision } & 71 \\ \text { Withdrawn } & 3 \\ \text { Closed } & 25 \\ \text { Transferred } & 4 \\ \text { Total } & 401\end{array}$

As its size has grown, problems with the automatic sorting machines used by the U.S. Postal Service were experienced. As a result, some members were receiving "mangled" copies of the journal.

In our continuing efforts to keep the quality of Optical Engineering high as it grows in size, we will be shrinkwrapping the journal so that it arrives in your mailbox in good shape. We hope this will alleviate the problems some of you have been experiencing in the last few months and that you will continue to receive copies of the journal that you will be proud to display on your bookshelves.

\section{Editor's Anecdote}

I often track down reviewers by telephone. On one occasion recently I was speaking to a distinguished colleague about his delinquency. He was not sure where the paper was and said "we have a system here that is designed to lose any manuscript." Our paper was no exception!

Brian J. Thompson

Editor 
May 1994

Semiconductor Infrared Detectors

Antoni Rogalski

Military Technical Academy

Institute of Technical Physics

Kaliskiego St. 25

01-489 Warsaw 49, Poland

$4822369109 \cdot 4822362254$ FAX

Optical Interconnects and Packaging

Sing Lee

University of California/San Diego

E\&CE Department

La Jolla, CA 92093-0407

$619 / 534-2413 \cdot 619 / 534-1225$ FAX

\section{June 1994}

Optical Science \& Engineering in India

Rajpal S. Sirohi

Indian Institute of Technology

Applied Optics Laboratory

Physics Department

Madras-600 036, India

044-2351365 ext. 221 • 044-2350509 FAX

Optical Pattern Recognition

Joseph L. Horner

Rome Laboratory

EROP

Hanscom AFB, MA 01731-5000

$617 / 377-3841 \cdot 617 / 377-5041$ FAX

Bahram Javidi

University of Connecticut

School of Engineering

Department of Electrical and Systems

Engineering

Room 312, U-157

260 Glenbrook Road

Storrs, CT 06269-3157

203/486-4 203/486-3789 FAX

July 1994

$$
2867
$$

Adaptive Wavelet Transforms

Harold H. Szu

U.S. Navy

Naval Surface Warfare Center

Code R44

10901 New Hampshire Avenue

Silver Springs, MD 20903-5000

301/394-3097 • 301/394-3923 FAX

\section{August 1994}

Digital Image Recovery and Synthesis

Paul S. Idell

Rockwell International

Rocketdyne Division

MS SS46

P.O. Box 7922

Canoga Park, CA 91309-7922

818/586-8238 • 818/586-5295 FAX

E-mail: pidell@windance.rdyne.rockwell.com

September 1994

Optics in South Africa

Hannes Markusse

ELOPTRO

Institute of Atomic Physics

P.O. Box 869

Kempton Park 1620, South Africa
Maurice W. McDowell

CSIR/Production Technology Div.

Productiontek

P.O. Box 395

Pretoria 0001, South Africa

$27128413418 \cdot 27128412131$ FAX

\section{October 1994}

\section{Optics in Russia}

V. Ya. Panchenko

Scientific Research Center for Technological

Lasers

Russia Academy of Sciences

B-333, Gubkina, 3

117971 Moscow, Russia

E-mail: ilc@compnet.npimsu.msk.su

(095)135-54-30 • (095)334-02-01 FAX

\section{November 1994}

\section{Micro-Optics}

Chandrasekhar Roychoudhuri

University of Connecticut at Storrs

Photonics Research Center

MS-157, Room 312

260 Glenbrook Road

Storrs, CT 06269-3157

203/486-4816 • 203/486-3789 FAX

Manuscripts due April 1, 1994.

\section{December 1994}

\section{Optics in Ireland}

John Hegarty

C. D. Hussey

University of Dublin

Trinity College

Department of Pure and Applied Physics

Dublin 2, Ireland

+353-1-7022019 • +353-1-711759 FAX

Manuscripts due May 1, 1994.

\section{January 1995}

\section{X-Ray/EUV Optics}

Richard B. Hoover

NASA Marshall Space Flight Center

ES52 Space Science Center

Huntsville, AL 35812-0001

E-mail: hoover@ssl.msfc.nasa.gov

205/544-7617 • 205/544-5856 FAX

Manuscripts due June 1, 1994.

\section{February 1995}

High Heat Flux Optical Engineering

Ali M. Khounsary

Argonne National Laboratory

Advanced Photon Source, APS 362

Argonne, IL 60439

708/252-3384 • 708/252-3222 FAX

Manuscripts due July 1, 1994.

March 1995

Optical Engineering in Ophthalmology

Suganda Jutamulia

Kowa Company, Ltd.

Silicon Valley Office

100 Homeland Court, Suite 302

San Jose, CA 95112

408/441-9300 • 408/441-0537 FAX
Toshimitsu Asakura

Hokkaido University

Research Institute for Electronic Science

Sapporo, 060 Japan

81-11-716-2111 • 81-11-758-3173 FAX

Manuscripts due Aug. 1, 1994.

April 1995

Optics in the Ukraine

Oleg V. Angelsky

Chernovtsy University

Department of Correlation Optics

2 Kosyubinsky Street

274012 Chernovtsy

Ukraine

(03722) 44730 • (03722) 41314 FAX

Manuscripts due Aug. 15, 1994

July 1995

Optics in Switzerland

P. K. Rastogi

Swiss Federal Institute of Technology-Lausanne

Laboratory of Stress Analysis

CH-1015 Lausanne

Switzerland

E-mail: rastogi@elgc.epfl.ch

(021) $6932445 \cdot(021) 6934748$ FAX

Manuscripts due Nov. 15, 1994

September 1995

Optical Science \& Engineering in Finland

Seppo Honkanen

Nokia Research Center

P.O. Box 156

SF-02101 Espoo

Finland

+358043761・+3580455 2557 FAX

Manuscripts due Jan. 15, 1995

November 1995

Optical Remote Sensing and Image

Processing

Mohammad A. Karim

Bradley D. Duncan

University of Dayton

Center for Electro-Optics

300 College Park

Dayton, OH 45469-0227

$513 / 229-2241 \cdot 513 / 229-3177$

513/229-2471 FAX

Manuscripts due April 1, 1995

December 1995

Optics in Polymer Science and Technology

Maksymilian Pluta

Institute of Applied Optics

Kamionkowska 18

03-805 Warsaw, Poland

(4822) 184405 • (4822) 133265 FAX

Andrzej Wasiak

Institute of Fundamental Technological Research

Polish Academy of Sciences

Savietokrzyska 21

00-012 Warsaw, Poland

(4822) 269815 FAX

Manuscripts due April 1, 1995. 